\title{
Harmonics of CFL and LED lamps - Maximum Penetration Perspective on Power Quality in Distribution Systems
}

\author{
Francis Boafo Effah $^{1^{*}}$, Philip D. Gasu ${ }^{1}$, Philip Okyere ${ }^{1}$ and Amevi Acakpovi ${ }^{2}$ \\ ${ }^{1}$ Department of Electrical and Electronic Engineering, Kwame Nkrumah University of Science and \\ Technology, Kumasi, Ghana \\ ${ }^{2}$ Department of Electrical and Electronic Engineering, Accra Technical University, Accra, Ghana \\ *Corresponding author, e-mail: fbeffah.coe@knust.edu.gh
}

\begin{abstract}
Global energy saving efforts have led to replacement of incandescent lamps with energy-efficient ones like light-emitting diode (LED) and compact fluorescent lamps (CFLs). These lamps, being non-linear loads, have the potential of injecting harmonics into distribution networks. In this paper, harmonics injection of common CFL and LED lamps at a facility point of common coupling is investigated. To gain insight into large scale penetration effects on power quality, field measurement results of popular lamps used in Ghana were replicated in MATLAB/Simulink through simulation. The field results showed that LED lamps exhibit more harmonics compared to CFL lamps. Maximum possible loading on a $100-\mathrm{kVA}, 11 \mathrm{kV} / 0.433 \mathrm{kV}$ distribution transformer was found to be $24.02 \%$ for CFL, $27.14 \%$ for LED, and $40.91 \%$ for a mixture of the two lamps, respectively, in order not to violate IEEE 519-2014 standard. The influence of other common loads such as ceiling fans on the lamps' harmonics were assessed in the field measurement. The use of ceiling fans with the lamps in the facility reduced the harmonics and improved the power factor of the facility. Since the lamps exist in residential and commercial facilities with other loads, more penetration of energy-saving lamps in the distribution system will have little influence on power quality.
\end{abstract}

Keywords: Compact fluorescent lamps, light emitting diodes, maximum power loading, total harmonic distortion, point of common coupling

\section{Introduction}

With an increased awareness of energy conservation, incandescent lamps (ILs) were identified to be wasteful in energy consumption. This led to worldwide governmental policy on prohibition of ILs, giving way to the use of compact fluorescent lamps (CFLs) and light emitting diode (LED) lamps [1]. CFL and LED lamps are noted to be energy-saving, efficient and last longer than ILs. However, the evolution of energy-efficient lamps, particularly, CFL and LED lamps were met with an open rejection on the grounds that their integration into power systems would lead to increase in total harmonic distortion (THD) [2]. These lamps are made from non-linear solid-state devices such as diode rectifiers and are operated on switching techniques $[3,4]$. These devices and the switching techniques upon which they are operated are potential sources of harmonics in the power distribution system [5].

Technically, effects of harmonics in power system come through line current and voltage distortions [6]. Power system harmonic effects include frequent tripping of protective devices, high neutral-to-earth voltages, reading error in energy meters and overheating of transformers, among others [7-9]. In 2017, harmonic currents contributed to over $100 \%$ increase in technical losses of distribution transformers in the Electricity Company of Ghana's (ECG's) distribution zones [7]. The system losses resulting from the harmonics threaten the financial sustainability and operational efficiency of utility companies. In ECG operation zone, the cost of energy resulting from the harmonic losses is found to be US\$ 555,098.78 per year [7].

On the harmonics of the lamps, most of the studies reported in the literature investigated the harmonics of the lamps either by taking measurements of their harmonic characteristics in laboratory installation or through experimental setups. The lamps' harmonics were measured at the terminals of the lamps to determine their harmonic injections into the power distribution system. In 
some studies, mathematical models were used to determine the harmonic injections and their effects on power system distribution network $[10,11]$. Since the ban of ILs in Ghana, there has been an influx of imported energy-saving lamps into the country with few manufactured locally. There appears to be no details on the power quality of the lamps and no clear control of their power quality [12].

Ghana's power distribution system has been undergoing constant improvements; where long radial $11 \mathrm{kV}$ lines routed from district substations are intercepted with $100-200 \mathrm{kVA}$ transformers to improve the voltage level for consumers to meet the ever-increasing loads [13]. Research results on the harmonics of energy-efficient lamps have shown that the harmonic levels increase with increase in the supply voltage $[14,15]$. This, in addition to the evidence of increase in harmonic currents in the Ghana power distribution system [7], calls for an investigation of CFL and LED lamps' harmonics impact on the Ghana power distribution system.

The authors in [16] researched and analyzed harmonic distortion of IL and CFL lamps on residential consumers and reported that there was substantial increase of current harmonic injection into the supply. Matvoz, et.al [17] by simulation developed a model of electricity network and investigated the effect of LED and CFL lamps in connection with other loads. The simulation results revealed that there is a considerable harmonic voltage distortion in the system. Jabbar et al [1] in an experimental investigation found out most CFLs produced about $120 \%$ of current harmonic distortion which could significantly affect supply power quality. McLorn et al. [14] studied the nonlinear characteristics of CFL and LED lamps notably on how their behavior varies with supply voltage level. Experimental measurement was undertaken in the laboratory. The obtained data from the measurement was used to formulate polynomial load model in a ZIP format which featured active power, reactive power and harmonic current flow behaviors. From the results and discussion, the paper concluded that these CFL and LED lamps have poor harmonic performance and that their proliferation would bring about high technical losses on low voltage networks and high operational cost to utilities.

As stated, most works on the lamps' harmonics investigation were based on taking their harmonics measurement in laboratory installation and others through experimental set-ups by taking the harmonics measurement at the input terminals of the lamps. To the best of our knowledge, no work has been done to assess the impact of CFL and LED lamps at a facility point of common coupling (PCC). The harmonics of these energy-saving lamps just as any other non-linear loads are recommended to be measured at a supply PCC for the mutual benefit of the user and utility provider. In commercial and residential installations, the lamps are distributed in the facility. It is believed that the lamps' individual harmonics influence could effectually converge at a common point - the PCC.

A measurement at a facility level PCC could possibly reflect the actual influence of the lamps' harmonics into the distribution system than the practice of individual lamp harmonic measurement at the input terminals. Therefore, there is a merit to investigate the harmonic distortion at the PCC since it is associated with the interaction between the utility supply system and the customer facility. This is justified by IEEE 519-2014 standard on Recommended Practices and Requirements for Harmonic Control in Electric Power Systems [18] as well as other standards [19, 20].

The approach by taking measurements at the PCC provides a comprehensive analysis of the distributed nature of the observed disturbance rather than the individual measurements of their harmonics as observed in the literature. Hence, this study proposes to contribute to existing knowledge on harmonics injection of energy-saving lamps by taking field harmonic measurements of the lamps at a facility PCC; use the obtained data to determine by simulation the maximum possible loading of each lamp with reference to IEEE std. 519-2014 voltage total harmonic distortion $\left(\mathrm{THD}_{\mathrm{V}}\right)$ limit of $8 \%$ on Ghana's power distribution system. Assessment by $[2,20]$ concluded that it is not clear what the growing use of energy efficient lamps has on power quality, and no power quality problems are expected for low penetration level. Therefore, the quest for the determination of maximum possible penetration level could provide perspectives into large scale influence of the lamps' harmonics on power quality of distribution systems.

The rest of the paper is organized as follows. Section 2 presents the methodology for the field measurements of CFL and LED lamps' harmonics in an installation. Simulations to match field measured values and predict maximum possible penetration that will not violate the $\mathrm{THD}_{\mathrm{v}}$ limit of 
$8 \%$ is given in section 3 . Results and discussions are presented in section 4 . Conclusions are given in section 5 .

\section{Methods used}

The IEEE 519-2014 standard recommends measurement of harmonic distortion at the PCC. The PCC is considered as a point in the power system closest to the customer where the utility power provider may tap the supply lines to provide power to another user. In low voltage distribution systems, the PCC is at the low voltage side of the service transformer. Typically, on pole mounted distribution systems for commercial and domestic facilities, the PCC could be the point at which the supply is connected to the customer's facility. An extension of the PCC in this case could be taken at the supply authority energy meter input terminal but not to be considered at the input terminal of an appliance within the building [19]. The essence of these designated points for the PCC, is for either the customer or the utility provider to assess the level of harmonic distortion so as to put in corrective measures in order that high levels of distortion does not affect the power quality of the neighbors on the same line.

In this work, harmonics of CFL and LED lamps were investigated at a facility PCC with HT 9022 power quality (PQ) analyzer. The PQ analyzer was placed at the input area of the energy meter at the facility. Figure 1 shows a picture of actual measurement of the lamps' harmonics. Forty-three CFL and LED lamps each from different manufacturers with power rating between $15 \mathrm{~W}$ to $26 \mathrm{~W}$ were acquired from the Ghanaian market. Among the 43 CFL and 43 LED lamps investigated, Focus CFL and Ant Electrical LED lamps were the common ones on the Ghanaian market. A sample of nine Focus CFL lamps were investigated. The following steps were taken:

1) after connecting the PQ analyzer at the facility PCC, all other appliances in the installation were switched off

2) the nine CFL lamps were connected one after the other progressively into lamp holders in the facility and their harmonic measurements taken and sent via Bluetooth to a laptop computer

3) afterwards, five $80 \mathrm{~W}$ ceiling fans in the facility were switched on and the harmonic measurement taken and transferred to the laptop computer

4) the captured data is then plotted as shown in Fig. 2 for the case of one CFL (A1), nine CFLs (A9) and nine CFLs plus five fans (A9+5Fans) in circuit, respectively.

Similarly, a sample of eight Ant Electrical LED lamps were used to study the harmonic effects of LED lamps at the facility PCC. The following steps were taken:

1) after connecting the PQ analyzer at the facility PCC, all other appliances in the facility were switched off

2) the eight LED lamps were connected sequentially from one lamp to eight lamps in lamp holders in the facility and their harmonic measurements taken and sent via Bluetooth to a laptop computer

3) afterwards, five $80 \mathrm{~W}$ ceiling fans in the facility were switched on and their harmonic measurement taken and sent via Bluetooth to the laptop computer

4) the data is then plotted as shown in Fig. 3 for the case of one LED lamp (M1), eight LED lamps (M8) and eight LED lamps plus five ceiling fans (M8+5Fans) in circuit, respectively.

A similar process was repeated for a combination of CFL and LED lamps. In this case, CFL and LED lamps were loaded in pairs of one up to five in the facility and the measurements taken. Figure 4 shows the current distortion and the supply voltage waveforms of one pair $\left(\mathrm{MA}_{1}\right)$ as well as five pairs of lamps $\left(\mathrm{MA}_{5}\right)$. The harmonic spectrum of the combined lamps is positioned to the right side of their respective waveforms. 

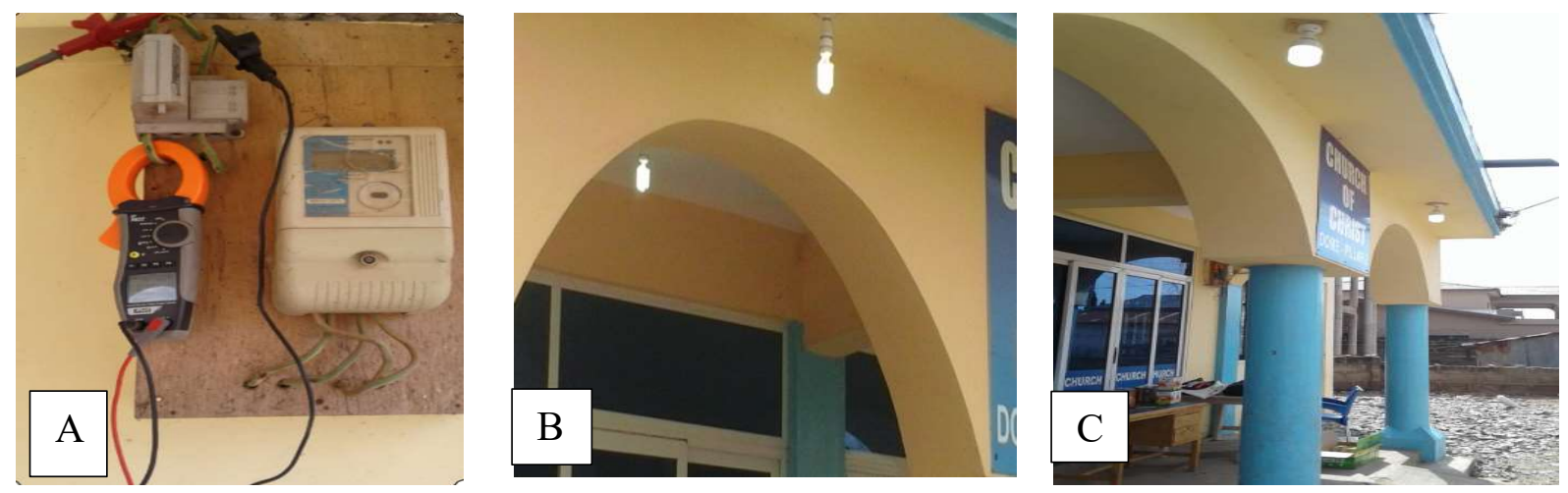

Fig. 1 Field measurement at facility PCC: A - power quality analyzer HT 9022 captures data and sends by Bluetooth to laptop, B-23W Focus CFL lamps in installation, C - 20W Ant Electrical LED lamps in installation

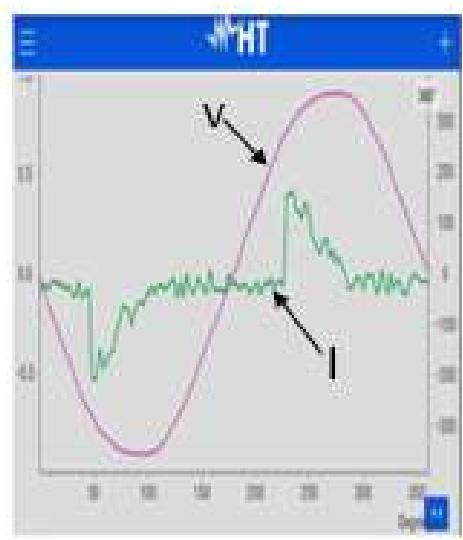

Al

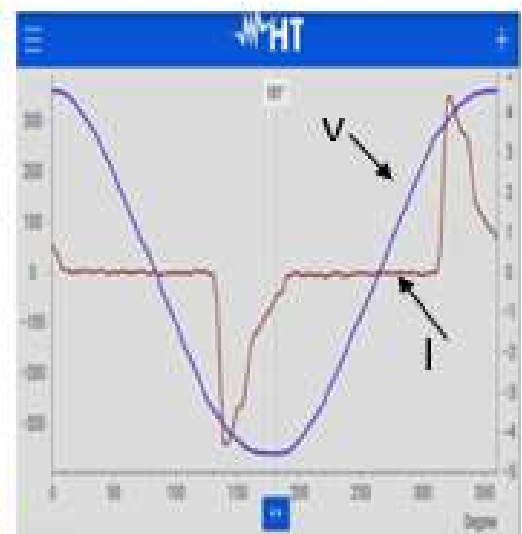

A9

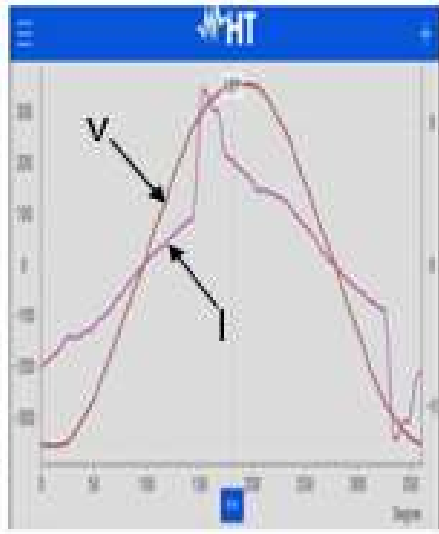

A $9+5$ Fan

Fig. 2 Voltage and current distortion at facility PCC due to presence of CFL lamps and ceiling fans in circuit

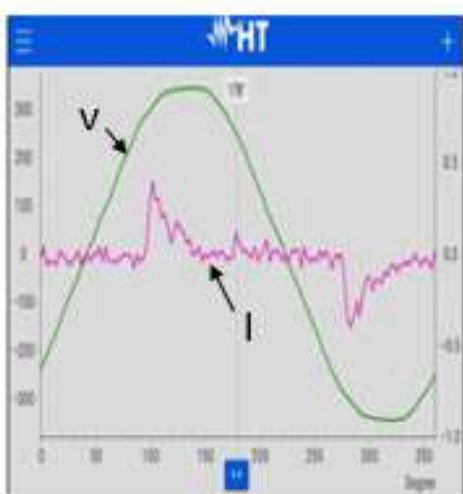

Ml

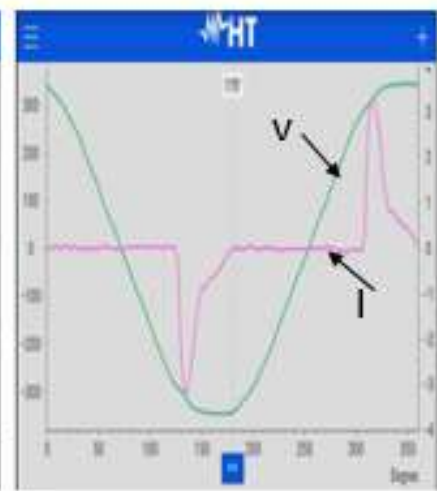

M8

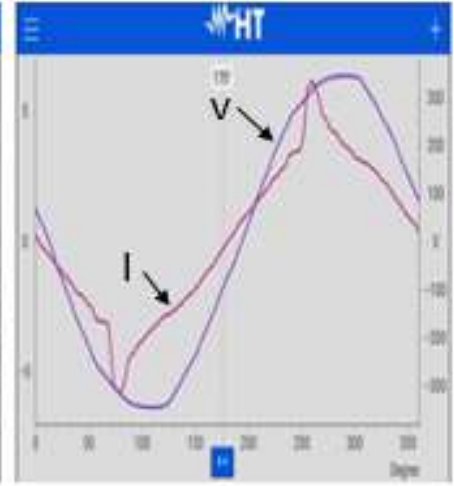

(M8 + 5Fans)

Fig. 3 Voltage and current distortion at facility PCC due to presence of LED lamps and ceiling fans in circuit 


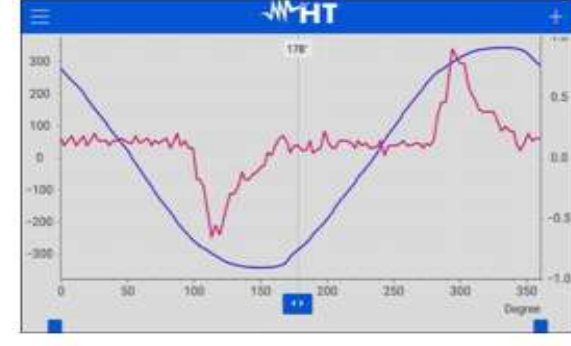

MA 1 Waveforms

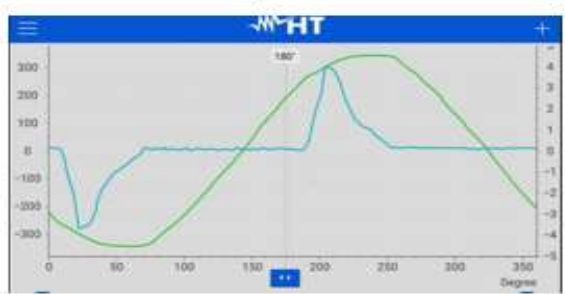

MAs Waveforms

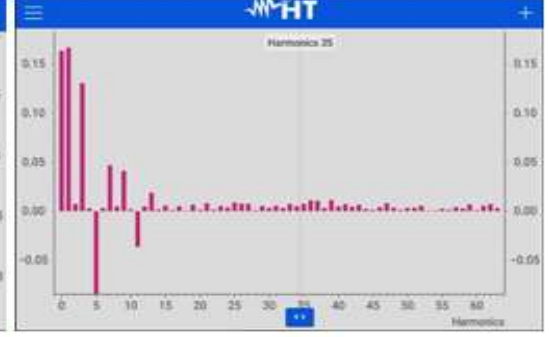

MA 1 Harmonic Spectrum

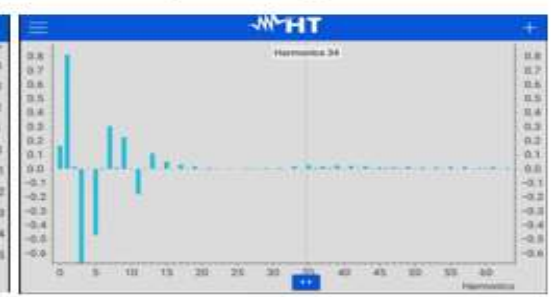

MA5 Harmonic Spectrum

Fig. 4 Harmonic waveforms and spectrum of the mixed lamps $\left(\mathrm{MA}_{1}-\mathrm{MA}_{5}\right)$

\section{Simulations to predict maximum penetration limits}

In order to predict the maximum possible penetration of the CFL and LED lamps on a local distribution transformer that will not violate the $8 \%$ $\mathrm{THD}_{\mathrm{V}}$ limit, simulations were carried out in MATLAB/Simulink. The area power network structure consisted of a $2 \mathrm{~km}, 11 \mathrm{kV}$ overhead lines from a nearby district power sub-station. The overhead lines are horizontally laid and equally spaced at $90 \mathrm{~cm}$ apart. The overhead line feeds the area 100-kVA pole-mounted transformer $(11 \mathrm{kV} / 0.433 \mathrm{kV}$ delta/star) which provides the area with 3-phase, 4-wire distribution lines. The 3phase, 4-wire lines are vertically mounted on pin insulators and spaced equally from each other at a distance of $30 \mathrm{~cm}$. The distance between adjacent poles is about $45 \mathrm{~m}$. The $433 \mathrm{~V}$ lines are composed of $120 \mathrm{~mm}^{2}$ All Aluminum Conductors (AAC).

The selected facility for the field harmonic measurement of the lamps is supplied with a singlephase line, connected from the 3-phase, 4-wire radial lines. The single-phase line is a $6 \mathrm{~m}$ by $25 \mathrm{~mm}^{2}$ PVC insulated AAC. The total length of cable supplying power from the transformer output to the energy meter input point of the building is about $30 \mathrm{~m}$. Figure 5 shows a simple diagram of the area network structure to the building. Possible points of common coupling are indicated as PCC1, PCC2 and PCC3. PCC2 is at the pole where the building supply was connected. Since PCC3 is the closest point to the consumer the field harmonic measurement of the lamps was taken at that point [18].

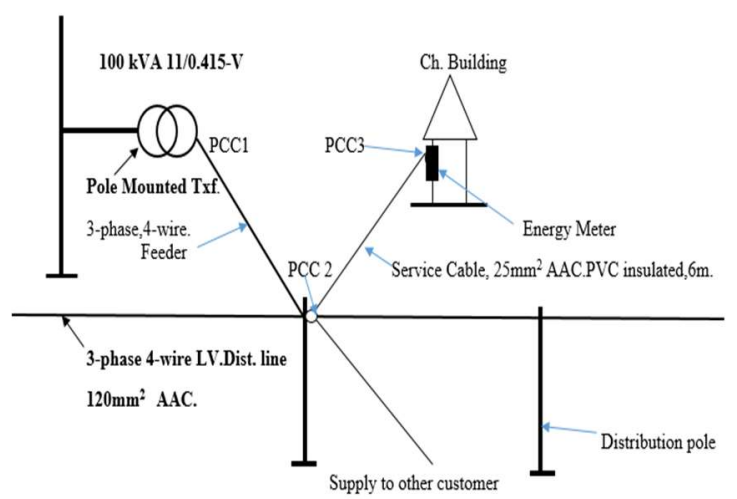

Fig. 5 Area network structure of the selected facility

The components of the network structure are represented by the single line diagram shown in Fig. 6.

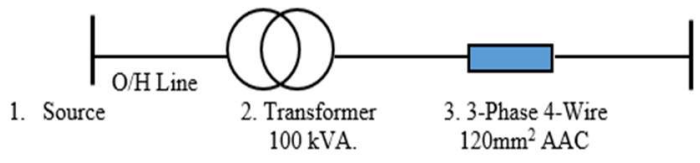

Fig. 6 Network single line diagram 
The utility company provided the upstream short circuit current $\left(\mathrm{I}_{\mathrm{SC}}\right.$ ) as $3263 \mathrm{~A}$ at a distance of $2 \mathrm{~km}$ from their nearby sub-station to the local area network transformer. The power source component parameters were determined using (1) and (2) where $\mathrm{V}_{\mathrm{L}}$ represents the primary line voltage [19, $20]$.

$$
\begin{aligned}
& \text { Fault VA }=\sqrt{3} \times \mathrm{V}_{\mathrm{L}} \times \mathrm{I}_{\mathrm{SC}} \\
& \mathrm{Z}_{\mathrm{S}}=\frac{\mathrm{CV}_{0}{ }^{2}}{\text { Fault VA }}
\end{aligned}
$$

In (2), $Z_{S}$ represents the source impedance in ohms, $V_{0}$ is the nominal line-to-line source voltage, and $C$ is the voltage factor. For a $230 / 415 \mathrm{~V}$ system $C$ equals 1 , for a system with $1 \mathrm{kV}$ to $250 \mathrm{kV}, C$ equals 1.1 , and $C$ equals 1.05 for other low voltages.

The primary and secondary windings parameters of the service transformer were determined with the length of the $2-\mathrm{km}$ overhead transmission lines from the substation to the input of the transformer. The obtained primary windings values were referred to secondary side to obtain secondary winding parameters. The overhead distribution line (19 strands, $120 \mathrm{~mm}^{2}$ AAC) with resistance of $0.2459-\Omega / \mathrm{km}$ and a geometric mean radius $(\mathrm{GmR})$ of $5.06 \mathrm{~mm}$ were obtained from manufacturer's data sheet. The spacing of the overhead conductor is $90 \mathrm{~cm}$. The geometric mean diameter is calculated using (3), where $\mathrm{D}_{\mathrm{RY}}$, $\mathrm{D}_{\mathrm{YB}}$ and $\mathrm{D}_{\mathrm{BR}}$ represent the distances between the red and yellow, yellow and blue, and blue and red phases, respectively. The inductance of the overhead line $\mathrm{L}_{1}$ was obtained using (4).

$$
\begin{aligned}
& \left.G m D=\sqrt[3]{\left(D_{R Y} \times D_{Y B} \times D_{B R}\right.}\right) \\
& \mathrm{L}_{1}=10^{-7}\left(0.5+2 \ln \left[\frac{G m D}{G m R}\right]\right) H / m
\end{aligned}
$$

The distribution line was modeled using the $\pi$ equivalent circuit. The line resistance and inductance values were determined from manufacturers data sheet whilst the capacitance value was determined using (5).

$$
\boldsymbol{C}=\frac{2 \pi \varepsilon_{o}}{\operatorname{In}\left(\frac{G m D}{r}\right)}, \mathrm{r}=7.0 \times 10^{-3} \mathrm{~m}
$$

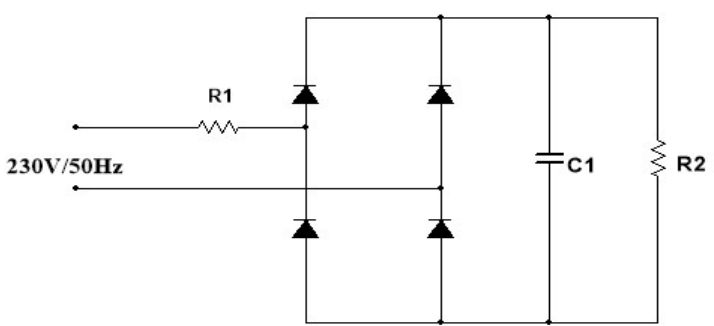

Fig. 7 Model for CFL and LED lamps

The model for simulating both the CFL and LED lamps' harmonics is shown in Fig. 7. The model parameters were determined using the procedure given in $[21,22]$. According to [21 - 23], the value of R1 could be estimated using (6).

$$
R 1=0.2868 \times 0.6852 P_{C F L_{L} L E D}
$$

The DC capacitor $\mathrm{C} 1$ and resistor $\mathrm{R} 2$ values, according to [21] could also be estimated by (7) and (8), respectively.

$$
\begin{aligned}
& C 1=0.24 \times 10^{-6} P_{C F L_{-} L E D} \\
& R 2=\frac{3.924 \mathrm{~V}}{I}
\end{aligned}
$$

In (6), (7) and (8), $\mathrm{V}, \mathrm{I}$ and $\mathrm{P}_{\mathrm{CFL} \text { LED }}$ refer to the rated voltage or operating voltage, measured fundamental current, and rated power of the CFL and LED lamps, respectively. In the absence of the measured fundamental current I, the value could be estimated using the rated current of the lamp as:

$$
I=0.85 \times I_{R}
$$

where $I_{R}$ is the rated current of the lamp.

Table I Parameters for CFL and LED lamps

\begin{tabular}{|l|c|c|c|}
\hline \multirow{2}{*}{} & \multicolumn{3}{|c|}{ Parameter Values } \\
\cline { 2 - 4 } & $\begin{array}{c}\mathrm{R}_{1-} \\
(\Omega)\end{array}$ & $\begin{array}{c}\mathrm{C}_{1-} \\
(\mu \mathrm{F})\end{array}$ & $\begin{array}{c}\mathrm{R}_{2-} \\
(\Omega)\end{array}$ \\
\hline $\begin{array}{l}\text { Lamps } \\
\text { 1. Focus 23W } \\
\text { CFL }\end{array}$ & 23.4 & 5.6 & 3460 \\
\hline $\begin{array}{l}\text { 2. Ant Electrical } \\
\text { 20W LED }\end{array}$ & 16.57 & 5.14 & 5341 \\
\hline
\end{tabular}

On the basis of (6) to (9), the model parameters of the Focus 23W CFL lamp were determined using its field measured power of $30 \mathrm{~W}$ instead of $23 \mathrm{~W}$ on its label. For the Ant Electrical 20W LED, its field 
measured value was found to be $20 \mathrm{~W}$ so this value was used in the calculations. Table I shows the model parameters for the two chosen energy-saving lamps. Each of the models' three parameters were tuned in the simulation until the lamps' field measured values matched the simulated values.

Total harmonic distortion (THD) is the amount of harmonic distortion in a signal. This is quantified as the ratio of the sum of powers of all harmonic components to the power of the fundamental frequency. THD is the commonly used index to quantify current and voltage distortion in power systems. Current total harmonic distortion $\left(\mathrm{THD}_{\mathrm{I}}\right)$ and voltage total harmonic distortion $\left(\mathrm{THD}_{\mathrm{V}}\right)$ values show the level of distortion in the current and voltage waveforms with respect to pure sine waves. The implication on levels of each quantity of distortion has been given by [21]. The recommended power factor requirement for lamps' power rating is also given in IEC 62612-2013 [24]. A low power factor of a lamp implies more current is drawn than needed by the lamp. This leads to higher electricity bills. The level of current and voltage harmonic distortions present in a power system are given by (10) and (11), respectively.

$$
\begin{aligned}
& \operatorname{THD}_{I}(\%)=\frac{\sqrt{\sum_{h=2}^{n} I_{h}^{2}}}{I_{1}} \times 100 \\
& \operatorname{THD}_{V}(\%)=\frac{\sqrt{\sum_{h=2}^{n} V_{h}^{2}}}{V_{1}} \times 100
\end{aligned}
$$

In (10), $I_{1}$ is the fundamental rms value of the current waveform, $\mathrm{I}_{\mathrm{h}}$ refers to the rms value of the current harmonic of order ' $h$ ', while ' $n$ ' is the highest harmonic order present in the current waveform. Similarly, $V_{1}$ refers to the fundamental rms value of the voltage waveform, $V_{h}$ denotes the rms value of voltage harmonic with harmonic order ' $h$ '. With the presence of harmonics in power systems, power factor (pf) is defined as the product of displacement factor (dpf) and distortion factor $(\varphi)$, with these indices defined as:

$$
\begin{aligned}
& \varphi=\frac{\mathrm{I}_{1}}{\mathrm{I}_{\mathrm{RMS}}}=\frac{1}{\sqrt{1+\mathrm{THD}_{\mathrm{i}}^{2}}} \\
& p f=\frac{\cos \theta}{\sqrt{1+T H D i^{2}}}=\varphi \times d p f
\end{aligned}
$$

In (12), $\mathrm{I}_{\mathrm{RMS}}$ refers to the total rms value of the current waveform. The angle $\theta$ is the phase difference between the fundamental components of the current and voltage waveforms. With all the network parameters represented and power quality (PQ) model obtained in MATLAB/Simulink, the lamp model was tuned to obtain values close to the field measured ones. The tuning process is as shown in the flow chart of Fig. 8. In the chart, a single-phase voltage (1ph volt.) was obtained from a 3-phase supply, for the lamp model. As the model went through simulation, field measured (Fm) values such as power, displacement factor, power factor, $\mathrm{THD}_{\mathrm{V}}$ and $\mathrm{THD}_{\mathrm{I}}$ were compared with the simulation generated values until the simulation and field measured results were similar. From here, the simulation was advanced to where the modeled lamps were connected progressively onto the formulated network. The lamp model as shown in Fig.7 cannot be used for successive loading of the lamps from one to higher values on the modeled grid. Masking in MATLAB/Simulink allows the lamp model to be compressed to a small size. With the compressed lamp model, the lamps were loaded equally across each phase in ones, tens, hundreds, etc. and simulated. The rms values were recorded and the $\mathrm{THD}_{\mathrm{v}}$ values evaluated. The CFL and LED lamps and the combination of the two were simulated in turns to the maximum limit of $8 \%$ THDv.

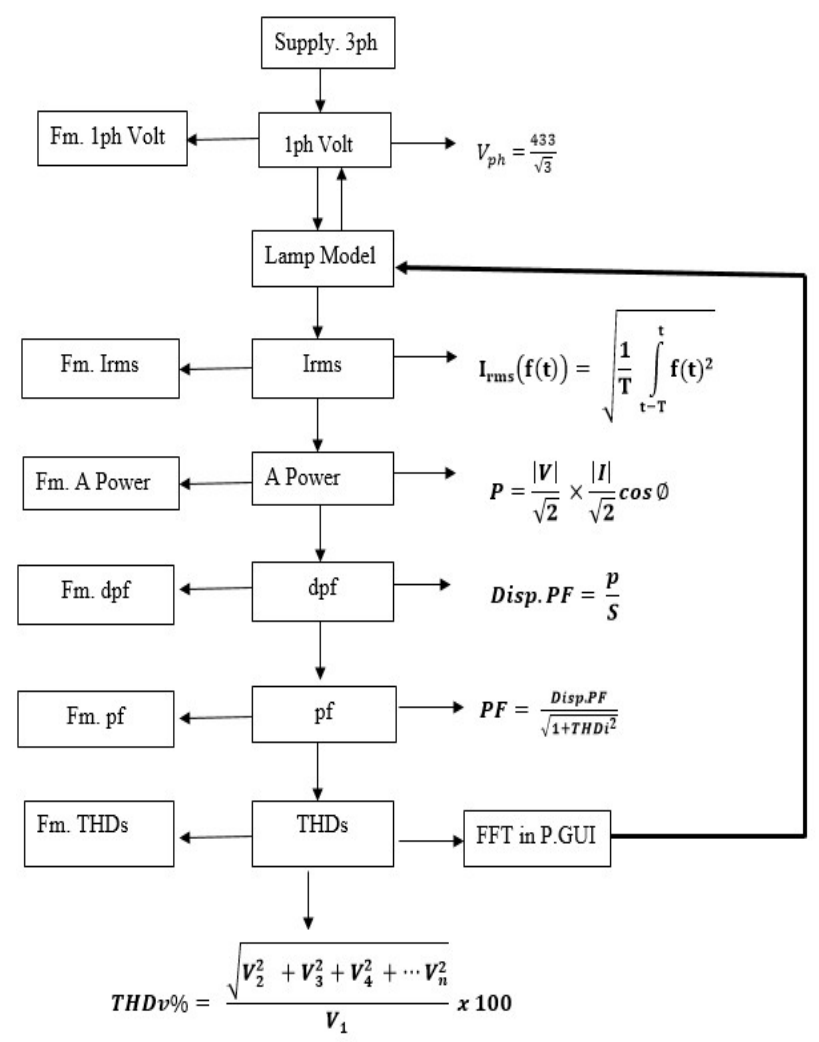

Fig. 8 Lamp model parameter tuning 


\section{Results and discussion}

In this section, the simulated results for the Focus CFL lamps, Ant Electrical LED lamps and mixture of the two are presented. There were nine Focus CFL lamps, eight Ant Electrical LED lamps and five pairs of the combined lamps. As described in section 2, the lamps were loaded onto the modeled supply network one after the other. Thus, when one lamp is connected in circuit, the simulation was carried out and the values recorded, then the next lamp was added to the first in the circuit and the simulation ran again. The process was repeated until the last lamp.

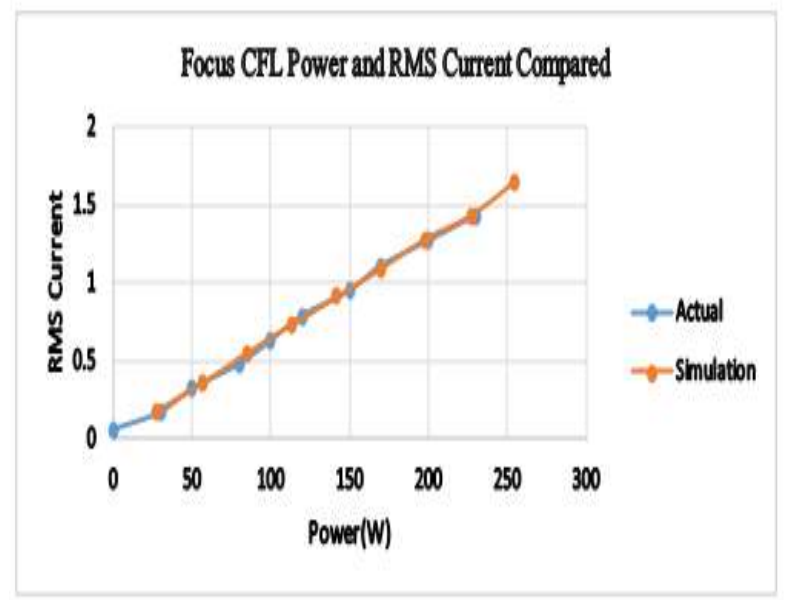

Fig. 9 Comparison of simulated results with field measured results for Focus 23W CFL lamps

Figure 9 presents a graphical comparison of the simulated and field measured results for the Focus $23 \mathrm{~W}$ CFL lamps, in terms of rms currents and power. It is clear the two graphs match closely. A similar graph for the 20W Ant Electrical LED lamps is shown in Fig. 10 where the correlation of the two graphs is very clear.

In the simulation to determine the maximum possible loading limit, the same procedure was adopted but the lamps were loaded in ones, tens, hundred, etc. until the $8 \% \mathrm{THD}_{\mathrm{V}}$ was attained.

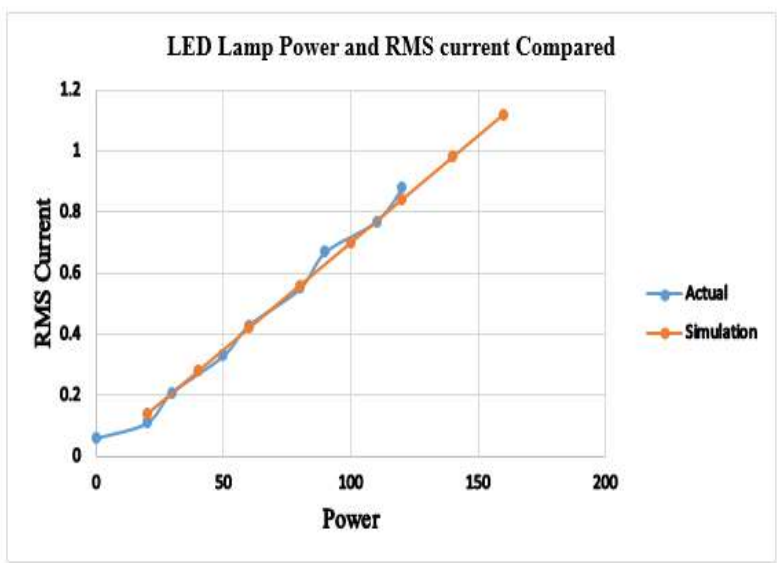

Fig. 10 Comparison of simulated results with field measured results for Ant Electrical 23W LED lamps

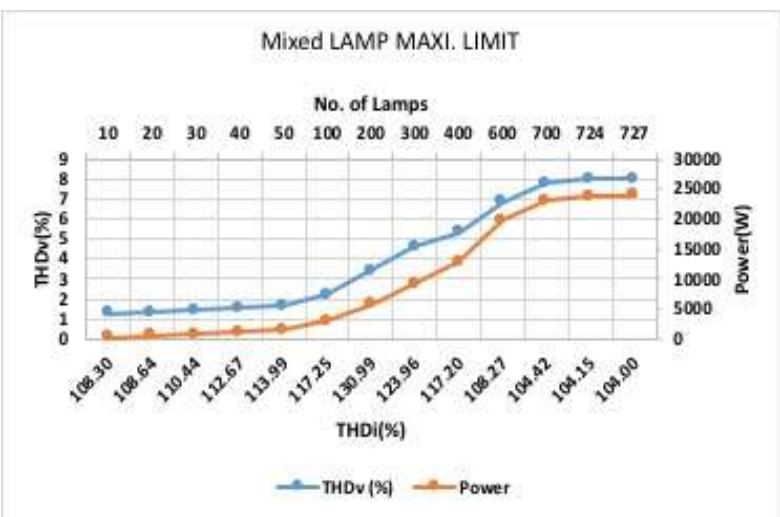

Fig. 11 Maximum possible loading limit of CFL lamps

From Fig. 11, the $8 \% \mathrm{THD}_{\mathrm{V}}$ limit was attained with 724 of the Focus 23W CFL lamps. The maximum power at the limit was $24.02 \mathrm{~kW}$. It is evident from this graph that as more CFL lamps are added to the circuit, the $\mathrm{THD}_{\mathrm{V}}$ values remain relatively low, around $1.0-1.5 \%$ when the number of lamps is less than 100. However, as hundreds of lamps are added, the rise in $\mathrm{THD}_{\mathrm{v}}$ values become more pronounced reaching the $8 \%$ limit in no time. There is also a close correlation between the power drawn by the lamps and the $\mathrm{THD}_{\mathrm{V}}$ injected into the network. The variation of the $\mathrm{THD}_{\mathrm{I}}$, however, remains within a tight window of $104-108 \%$ as more lamps were added and the power consumption increased. 


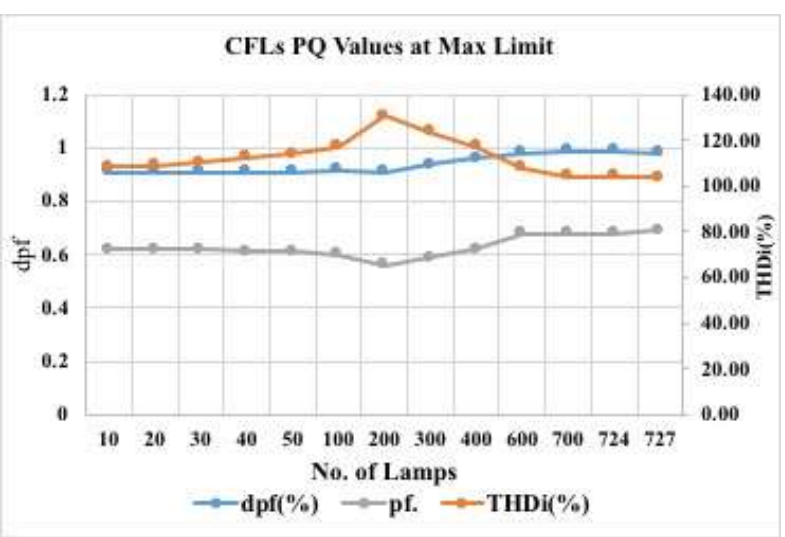

Fig. 12 Power quality values of CFLs at maximum loading limit

Figure 12 presents the power quality in terms of displacement power factor (dpf), power factor (pf) and $\mathrm{THD}_{\mathrm{I}}$ of the CFL lamps in relation to more lamps' penetration in the network. As can be clearly seen from the graph, with the lamps' load increased from 10 , the $\mathrm{THD}_{\mathrm{I}}$ increased steadily up to 200 lamps and begun to decrease. The dpf also increased and remained steady from 0.91 to unity. The $\mathrm{pf}$ in this regard declines somehow and rises as the lamp load increases and $\mathrm{THD}_{\mathrm{I}}$ decreases. The dpf and pf values are better from 600 lamps penetration. $\mathrm{THD}_{\mathrm{I}}$ declines with increasing loads.

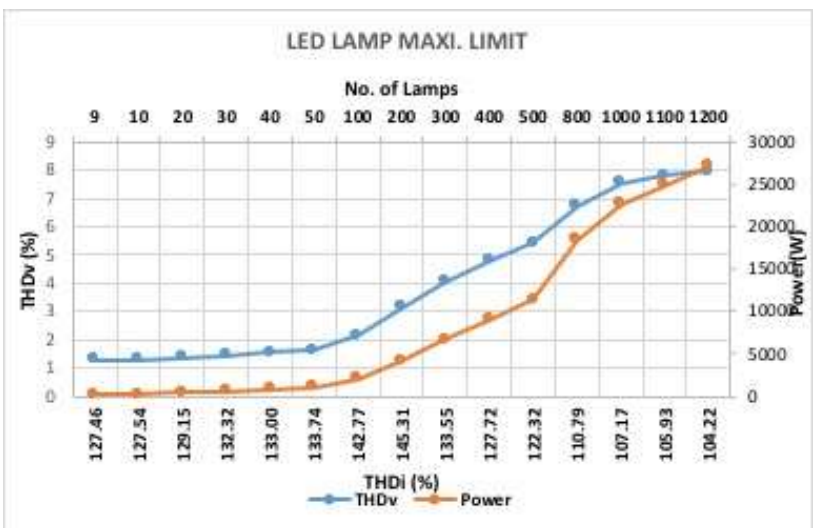

Fig. 13 Maximum possible power loading limit of LED lamps

Similarly, the LED lamps were loaded equally to the phases of the network in tens, hundreds, etc. and simulated increasingly until the recommended $\mathrm{THD}_{\mathrm{v}}$ of $8 \%$ limit was attained at $7.97 \%$. From Fig. 13 , the $\mathrm{THD}_{\mathrm{V}}$ of $7.97 \%$ which is close to the recommended $8 \%$ limit was attained with a total of 1200 LED lamps. The maximum power at this value was $27.14 \mathrm{~kW}$.

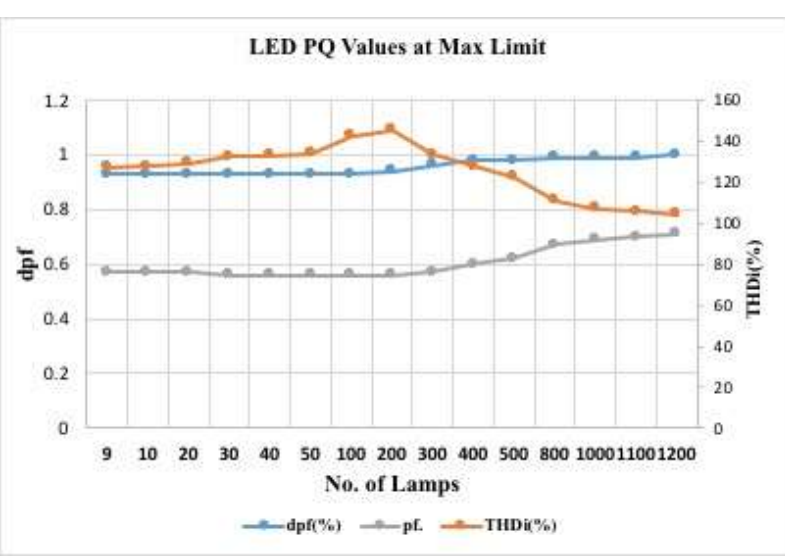

Fig. 14 Power quality values of CFLs at maximum loading limit

Figure 14 presents the power quality in terms of dpf, pf, and $\mathrm{THD}_{\mathrm{I}}$ of the LED lamps in relation to number of lamps. As the number of lamps increased from ten, the $\mathrm{THD}_{\mathrm{I}}$ increased steadily and started declining when the number exceeded 200 . The dpf remained steady in the region of 0.93 and increased gradually close to unity as was the case for the CFL lamps. The pf in this regard increased as the $\mathrm{THD}_{\mathrm{I}}$ decreased from 300 lamps penetration. The dpf and pf values are better from 400 lamps upwards as the $\mathrm{THD}_{\mathrm{I}}$ declines.

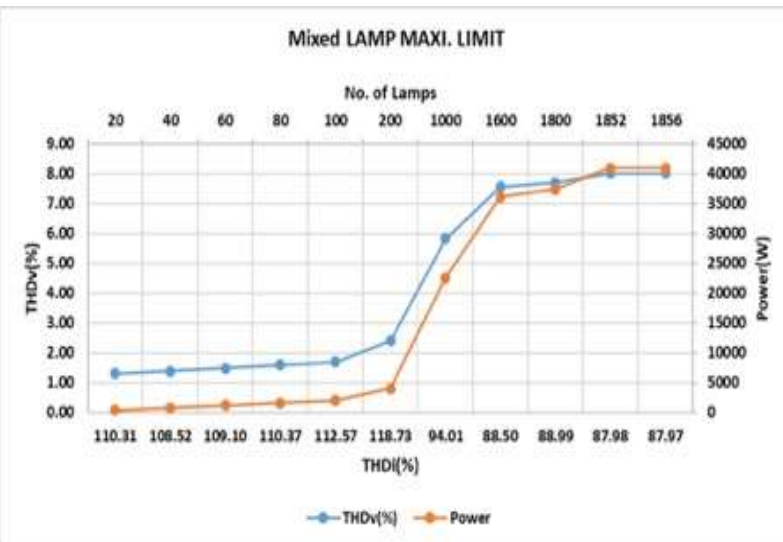

Fig. 15 Maximum possible power loading of the mixed lamps

The maximum power loading limit for the mixture of CFL and LED lamps was determined by loading equally across the phases from 10 pairs of lamps and simulated increasingly until the recommended $\mathrm{THD}_{\mathrm{v}}$ limit of $8 \%$ was attained at $8.01 \%$. The number of mixed lamps in circuit was 1852 (926 pairs). This corresponds to a total lamp power of $40.91 \mathrm{~kW}$. This is shown in the graph of Fig. 15. 


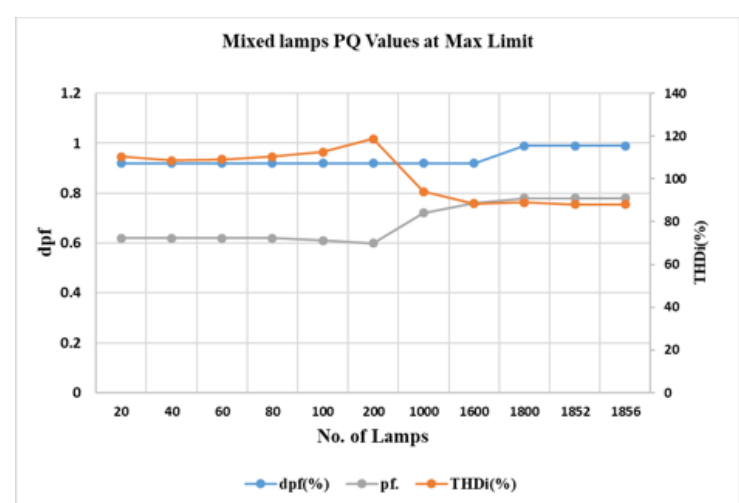

Fig. 16 Power quality values of the mixed lamps at maximum loading limit

As more lamp load penetrate, the power quality values of the mixture of CFL and LED lamps show improvement in both dpf and $\mathrm{pf}$. $\mathrm{THD}_{\mathrm{I}}$ values also drop with increasing lamp load. In Fig. 16, this is shown conspicuously as more lamps are loaded. From 200 lamps and above, the pf improved from 0.6 to 0.78 . Similarly, the dpf improved from 0.92 to 0.99 .

\section{Conclusion}

Harmonics of energy-saving lamps have been studied by many researchers through either laboratory installations or experimental set ups. Measurement of the lamps' harmonics are usually taken at the supply input of the lamps' terminals. This paper investigated the harmonics of CFL and LED lamps through field measurement at a facility point of common coupling as recommended by IEEE 519-2014 standard. A local network of $100 \mathrm{kVA}, 11 \mathrm{kV} / 0.433 \mathrm{kV}$ capacity was formulated in MATLAB/Simulink. The obtained field measurement of popular lamps used in Ghana such as Focus CFL and Ant Electrical LED lamps were replicated through simulation in MATLAB/Simulink.

Also, the influence of other loads such as ceiling fans on the lamps' harmonics were assessed. The maximum possible power loading limit with reference to the recommended $8 \% \mathrm{THD}_{\mathrm{V}}$ limit were obtained for each lamp through simulations. A maximum power of $24 \mathrm{~kW}$ was obtained for 724 , 23W Focus CFL lamps while 1200, 20W Ant Electrical LED lamps attained the maximum power limit at $27 \mathrm{~kW}$. Field harmonic assessment of the two lamp groups indicated that LED lamps are of lower power factor and exhibit more harmonics than CFL lamps. This is found to be in line with other research findings. However, more penetration of the lamps into the power distribution system shows an improved power quality. This was revealed by the simulation results. Since the lamps exist in residential and commercial facilities with other loads, more penetration of energy-saving lamps in distribution systems will have little influence on power quality.

\section{References}

[1] R. A. Jabbar, M. Al-Dabbagh, A. Muhammad, R. H. Khawaja, M. Akmal and M. R. Arif (2008). Impact of compact fluorescent lamp on power quality. In: Power Engineering Conference, 2008, AUPEC'08. Australasian Universities (pp. 1-5).

[2] Parsons Brinckerhoff Associates (2006), Wellington. "Installation of Compact Fluorescent Lamps Assessment of Benefits" Report for Electricity Commission, New Zealand, April 2006 pp (1-31), Section 2.7 http://www.electricitycommission.govt.nz/p dfs/opdev/elec-efficiency/cfl-reportApril06.pdf.

[3] P. N. Korovesis, G. A. Vokas, I. F. Gonos and F. V. Topalis (2004) "Influence of large-scale installation of energy saving lamps on line voltage distortion of a weak network supplied by photovoltaic station" IEEE Transactions on Power Delivery. Volume: 19, Issue: 4, Oct. 2004, pp. $(1787-1793)$ DOI: 10.1109/TPWRD.2004.835432.

[4] C. Calwell and T. Reeder (2012)" Power supplies: A hidden opportunity for energy saving" Natural Resources Defense council, May 2002 (pp.1-22)

[5] R. R. Verderber, O. C, Morse and W. R. Alling (1993), "Harmonics from compact fluorescent lamps" (pp.670 - 674). IEEE Transaction on Industry Applications, Vol 29. No.3, May/June 1993.

[6] A. Fehér, and Z. Puklus (2007) "Definitions and measurement of power factor". In Proceeding of 8th International Symposium of Hungarian Researchers on Computational Intelligence and Informatics, (pp. 623-632).

[7] G. Eduful and K.J. A. Atanga, (2017) "Evaluating the performance of Harmonic Neutral Blocking Filter in ECG Electric Power Distribution System," vol. I, pp. 7-10, 2017. 
[8] T. M. Lee, and T. M. Chan (1995) "The effect of harmonics on the operational characteristics of residual-current circuit breakers," proceedings of EMPD'95, Vol. 2, Nov.1995, pp.548-553

[9] J. C. Balda, A.R. Oliva, D.W. McNabb, R.D. Richardson (1997) "Measurements of neutral currents and voltages on a distribution feeder, IEEE Transactions on Power Delivery, Volume 12, No. 4 October 1997

[10] D. J. Pileggi, E. M. Gulachenski, C. E. Root, T. J. Gentile, and A. E. Emanuel (1993). The effect of modern compact fluorescent lights on voltage distortion. IEEE Transactions on Power Delivery, 8(3): 1451-145

[11] V. George, A. Bagaria, P.h Singh, S. R Pampattiwar and S. Periwal, (2011) "Comparison of CFL and LED Lamp Harmonic Disturbances, Economics (Cost and Power Quality) and Maximum Possible Loading in a Power System (2011),"2011 International Conference \& Utility Exhibition on Power and Energy Systems: Issues and Prospects for Asia (ICUE), Pattaya City,2011, pp.15.doi:10.1109/ICUEPES.2011.6497742.

[12] REEP-Renewable Energy \& Energy Efficiency Partnership "Performance standards and labelling for LED lighting in Ghana" (2018). Wagramer Strasse 5 (Vienna International Centre, Room D-1861) A-1400 Vienna.

https://www.reeep.org/projects/performance -standards-and-labelling-led-lighting-ghana

[13] General News on Monday, 18 August 2003 "ECG to improve power distribution" https://www.ghanaweb.com/GhanaHomePa ge/NewsArchive/ECG-to-improve-powerdistribution-Nduom-41378

[14] G. McLorn, D. Laverty, D. J. Morrow, S. Mcloone (2019) "Load and harmonic distortion characterization of modern lowenergy lighting under applied voltage variation" Electric Power Systems Research,169 (2019) pp.124-139, journal www.elsevier.com/locate/epsr

[15] S. D. G. R. Faruq, A. B. Chowdhury (2016). A comparative study on harmonics of different electric bulbs. American Journal of Engineering Research (AJER) e-ISSN:
2320-0847 p-ISSN: 2320-0936 Volume-5, Issue-6, 156-166 www.ajer.org Research Paper Open Access.

[16] A. Gil-de-Castro, R. Medina-Gracia, S. K. Ronnberg, A. M. Blanco, and J. Meyer (2018) Differences in the performance between CFL and LED lamps under different voltage distortions, 2018 18th International Conference on Harmonics and Quality of Power (ICHQP);2018; 10.1109/ICHQP.2018. 8378918.pp(1-6)

[17] D. Matvoz, and M. Maksić (2012). Comparison of LED and CFL lamps and their impact on electric power network. IEEE 15th International Conference on Harmonics and Quality of Power (ICHQP), 320 - 327, Hong Kong.

[18] IEEE Std 519TM-2014 (Revision of IEEE Std 519-1992) IEEE Recommended Practice and Requirements for Harmonic Control in Electric Power Systems

[19] M.K. Giridharan, (2010) "Electrical Systems Design" (pp.1-368), International Publishing House Pvt, Ltd. ISBN 978-9380578-05-7.

[20] J. Philips, Arch Flash and Electrical Power Training [online]: accessed 18th March,2018. https://brainfiller.com/2018/03/18/shortcircuit-calculations-transformer-and-sourceimpedance/

[21] J. Yong, L. Chen, A. B. Nassif, and W. Xu (2010) "A Frequency-Domain Harmonic Model for Compact Fluorescent Lamps" IEEE Transactions on Power Delivery, Vol. 25, No. 2, pp.1183 -1189. April 2010.

[22] A. J. Collin, S. Z. Djokic, C. E. Cresswell, A. M. Blanco, J. Meyer, (2014) "Cancellation of Harmonics Between Groups of Modern Compact Fluorescent Lamps", International Symposium on Power Electronics, Electrical Drives, Automation and Motion, 978-14799-4749-2/14/\$31.00 (C2014 IEEE

[23] J. Molina, and L. Sainz (2014). Model of Electronic Ballast Compact Fluorescent Lamps, IEEE Transactions on Power Delivery, vol.29, no.3, pp1363-1371.

[24] Electrical Installation Guide, 2018 Edition, Section M4, pp (412-588), Soft-copy, Schneider Electric. 